\title{
Tritium as a marker for anthropogenic pollution and for the vulnerability assessment of groundwater systems
}

\author{
ANTONIETTA RIZZO ${ }^{1}$, DINO DI RENZO ${ }^{2}$, CHIARA \\ TELLOLI $^{1}$, STEFANO SALVI ${ }^{3}$ AND CARMELA VACCARO $^{2}$ \\ ${ }^{1}$ ENEA, Italian National Agency for New Technologies, Energy \\ and Sustainable Economic Development, Bologna Research \\ Centre \\ ${ }^{2}$ University of Ferrara \\ ${ }^{3}$ ENEA, Italian National Agency for New Technologies, Energy \\ and Sustainable Economic Development, Brasimone Research \\ Centre \\ Presenting Author: dino.direnzo@unife.it
}

The monitoring of Tritium concentration in groundwater is a very useful tool for the determination of recent exchanges with surface water and of the presence of anthropogenic contributions.

Tritium $\left({ }^{3} \mathrm{H}\right)$ has both anthropogenic and origin cosmogenic: it is produced in nuclear weapon testing and in nuclear reactors and it is continuously generated by the interaction of high energy cosmic rays with oxygen and nitrogen atoms in the upper atmosphere.

These latter processes produce most of the world's natural tritium. It decades into a $\mathrm{He}$ atom $\left({ }^{3} \mathrm{He}\right)$ by emission of $\beta$ particles with a half-life of $12.32 \mathrm{yr}\left(\mathrm{T}^{1 / 2}\right)$.

The short period of residence in atmosphere and the small half-life imply that ${ }^{3} \mathrm{H}$ world steady state natural inventory is low and almost constant $\left(\sim 70 \times 10^{6} \mathrm{Ci}\right)$, although a greater production of ${ }^{3} \mathrm{H}$ during the atmospheric testing of nuclear bombs between 1951 and 1963 changed the geochemical footprint of rainfall by introducing anthropogenic tritium into the atmosphere and subsequently in the sea waters.

Tritium concentration in surface and groundwater is related to the amount of ${ }^{3} \mathrm{H}$ in the atmosphere and on the transfer time of rain waters from the surface to the groundwater.

The aims of this work are to underline the importance of ${ }^{3} \mathrm{H}$ measurements to evaluate the recharge balance of groundwater and the vulnerability of a specific groundwater to anthropogenic pollution, as pollution close landfills due to the presence of luminescent inorganic waste.

Considering that tritium decays exponentially, common analysis techniques are often unable to determine its content in aquifers older than 20-30 years. Therefore, to characterize older and slow recharging aquifer ( $\max 60-70$ years) it is necessary to apply enrichment strategies that allows to measure very low concentration of tritium.

The ${ }^{3} \mathrm{H}$ enrichment procedure and analysis with low-level liquid scintillation spectrometer, implemented in Italy by the ENEA's Traceability Laboratory (FSN-SICNUC-TNMT) will be showed and some experimental results will be discussed. 